Rebecca Henn | Caldieron, Miller | Constance Bodurow Stallmeyer, Dearborn | Seth Wiley | Brian Szymanik

\section{Emerging Visions for Sustainable Urbanization}

\author{
John C. Stallmeyer, University of Illinois, Urbana- \\ Champaign, School of Architecture \\ Lynne M. Dearborn, University of Illinois, Urbana- \\ Champaign, School of Architecture
}

Harsh critiques of the utopian visions of modernist architects have led many of today's designers to seek to fit their constructed responses into the mainstream culture (Schneekloth, 1998). While undoubtedly the works of most designers are grounded in the intention of making the world a better and more beautiful place, the underlying desire to fit in with the mainstream leads implicitly to confirming the status quo of the built environment. We believe that if designers are to move toward envisioning and creating more sustainable urban futures they must eschew the desire to fit in and carefully and methodically reconsider what is possible. To that end, in this paper we explore the motivations, methods and outcomes of five students in their penultimate design studio of the Masters of Architecture program at the University of Illinois at Urbana-Champaign. Using three measures, motivations, methods, and outcomes, as evidence we seek to understand how future designers, as they complete their education and embark on careers in the design professions, comprehend and envision an urbanization process that results in a sustainable urban future.

\section{Frame of Reference/Context}

Creating sustainable future urbanization will require the integration of multiple dimensions of the environment at a broad range of scales. We define the urban, in this context, in the broadest possible terms. Within this broad definition we include all forms of increasingly dense human habitation. These include development within already existing urban cores but also new modes for developing at the periphery and exurban fringe that seek new relationships between the urban and rural interface. This broadening serves to refocus on the process rather than the products of urban intervention and it is in the process that the greatest innovation and the most pressing questions may be addressed. If we believe that architects should play a role in the development of these future forms, then we must look beyond traditional disciplinary boundaries and must tightly weave new and existing research and supporting data and analysis into the design process. Methods and design processes employed by architects must focus on naturally and socially defined places (Thayer, 2003) rather than on objects as disconnected elements in a landscape (Canter, 1977). To tackle the complex and growing environmental, economic, and social issues that face even the most technologically advanced societies, we must, in an integrated manner, recognize and address the comprehensive nature of the issues implicit in the creation of a sustainable future. To shed light on the methods and design processes that would allow architects to focus on multi-faceted and multi-scalar dimensions of naturally and socially defined places, this article explores the work of five future practitioners who represent for us this new paradigm. In each case, these future practitioners, our students, were motivated to make a critical assessment of their project's context and to realize a form of existence that suggests a more viable and equitable future.

If there is going to be a sustainable future, students such as these will be important players. For these students, their penultimate studio was set up as an independent design thesis that allowed each student to identify the subject of his design investigation. Each student chose to work in a context with which he was intimately familiar as a result of his personal history and experience. As the faculty advisers for these students, we offered a framework which emphasized design responses that grow out of "the ecological, material and human character of place" (Van Der Ryn \& Cowan, 2007, p. 3) and which valued equitable resource use and eliminating the use of greenfield sites in urban development. This framework owes much to the bioregional and "life-place" perspectives articulated by David Orr (1994) and Robert Thayer (2003). It builds directly from three ideas outlined in Ecological Design (Van Der Ryn \& Cowan, 2007): "solutions grow from place," "design with nature" (p. 7273), and "scale linking" (p. 51). The latter goes against the professional's predisposition "to seeing process at a single scale, refracted through a single discipline's language, metaphors, and tools" (p.52). Scale linking allows promotion of the stability of life on the planet by "working with nature's own finely tuned scale-linking systems" (p. 53) and by understanding the interrelationships of human and natural systems that operate outside of a system of political boundaries.

While each student identified his project for his final graduate studio within a familiar knowledge realm, our job as advisors in this process was to assist each to understand the particular way he saw the world -- his own ontology -- and to investigate how one's personal ontology can responsibly influence design process. As the cases will show, the students' intimate knowledge of the context of their chosen project and the diversity of projects set within the faculty's theoretical framework allowed for rich discussion among the group and for the development of design responses that were able to engage the multiple dimensions of sustainable urbanization as we have defined it. 
Each student's individual focus was framed by the larger concerns of the studio, also requiring that each student incorporate research knowledge generated in a range of disciplines outside of architecture. We assisted each student in navigating the evidentiary underpinnings of these investigations by directing them to references on a broad range of significant topics in fields as diverse as hydrology, agricultural economics, sociology and demography, economics, planning and landscape architecture. We also helped them to understand how such research can be brought to bear on design interventions. Each student integrated research within his design process to ground his responses in the local conditions and contexts, thus offering the possibility of regenerating local cultures, ecosystems and resources that can support a sustainable, place-based future (Thayer, 2003).

For each future practitioner, personal experience and worldview has led him to question the dominant paradigm of development in a particular locale. These five examples incorporate heightened awareness of issues of scale and time, thus bringing a new sense of urgency to ecological, social, and economic sustainability. These cases highlight new urban development frameworks that address adequate and equitable standards of living for all members of society and for all living systems while not exceeding carrying capacities at linked scales, from the human to the global (Hamm \& Muttagi, 1998). Taking sustainable urbanization as a goal caused these five students to question implicit and explicit assumptions of the dominant development paradigm and to re-internalize costs, monetary and otherwise, of development that have long been externalized.

Each of these cases considers processes and outcomes not only in relation to an immediate client, but also responding to the impact on a larger group of stakeholders, a more global constituency. Each incorporates broader material considerations than most architectural design projects, suggesting for example that within the cost of transforming Mid-western farmland into suburban development we must consider the value of that land in the global food-production equation. Each of these projects questions common assumptions underlying design and development decision-making, for example that college dormitories are less expensive when a double-loaded corridor scheme is employed. Each project carefully foregrounds important issues of context, the ecological, social, cultural, and economic dimensions of place -- a unit of analysis with far more utility for considering sustainable urban futures than the single building. The process of developing these projects required the students to be enthusiastic participants but, as the next section illustrates, it also required the faculty advisers to ask questions that redirected students to other concerns and other scales when a proposed solution solved one problem at one scale but neglected related issues at linked scales. These cases demonstrate that the integrated response to multiple dimensions of the environment at a broad range of scales necessitates delineating a much wider boundary around the evidence that one brings to bear on a design proposal than perhaps has been the case historically for designers. This became evident for these future practitioners as they considered the personal motivations that brought them to their final selfidentified studio projects.

\section{Motivations}

The student's work was informed by two overarching motivations. First, each recognized that sustainable urbanization must encompass a broad array of measures that can only be implemented at multiple scales of intervention. These measures, fall into several categories including social, cultural, economic as well as ecological sustainability. This led to gathering information not only about physical context but also about social, cultural and economic context. This information was considered in an integrated manner both in analysis and in design. Second, the students were motivated by their individual history and experience. These focused them on the specific issues and contexts of their projects and infused their research and design interventions with a knowledge of the project context that went beyond what might typically be expected in a hypothetical design studio.

Camden Greenlee brought a personal familiarity and history to his project. Having recently experienced the sale of his family farm for development, Greenlee was motivated to understand the development and transformation of arable land. His early proposals sought design solutions that could more sustainably develop arable land like his family farm. Very early on we encouraged him to look beyond this development paradigm to the underlying question of arable land development itself and its value beyond a real estate potential. This research quickly brought him to the assertions that would guide his design investigations for the remainder of the project, that arable land is a finite resource and that the value of this land will become a critical variable in the future, as arable land becomes scarcer and less productive. Greenlee's design process proceeded based on the premise that current land development patterns externalize many such costs associated with the development of agricultural land. Through this research Greenlee moved beyond his initial position of "its going to be developed and there are better ways to do that" to one that recognized the necessity to eliminate the development of arable land while accommodating population growth. Thus he set out to find design solutions that had zero impact on arable acreage.

Steve Wallon's personal experiences also focused his project. As an undergraduate transfer student, Wallon resided in one of the largest dormitory complexes on the University of Illinois's Urbana-Champaign campus. His experience was one of social isolation in part as a result of the layout of buildings and site. Motivated by this personal history and the campus plans to construct a new complex on the site, Wallon set about recasting the problem based on measures of ecological and social sustainability. Wallon's initial interviews with administrators at campus housing suggested that the primary motivation for the form of the new 
dormitories and complex was initial construction costs. Through further investigation, he found that this maintained prevalent development patterns for student housing on many campuses, which do not reflect existing research on building forms that increase opportunities for student social interaction nor state of the art knowledge about ecology or energy consumption. Although the project questions centered on the social aspects of the campus housing, Wallon, like many others, easily fell into the mode of providing the technological solutions to easily defined issues of sustainability. Throughout the design process we were able, through the use of Wallon's own research on the subject, to question these solutions and refocus Steve on the issues that had motivated him to undertake the project in the first place, issues of social isolation and social sustainability.

Building from the premise that social equity is a key component of any sustainable future Alonso Alvarado's project focused on the provision of food and water to underserved segments of Mexico City's population. Motivated first by his family's history in the city and then by the need to understand one of the most difficult resource and infrastructure problems facing developing urban environments, Alvarado began by researching the ways that water has played a critical role in the history and infrastructure of the city. Approaching Mexico City's location in the bed of Lake Texcoco and the highly engineered solutions to moving water beyond the city, Alvarado investigated alternatives that would simultaneously clean water within the city's boundaries providing a much needed source of potable water for residents while also providing spaces for growing fresh produce within the city's neighborhoods. This approach led Alvarado to a large-scale infrastructure solution focused on provision of water to a large underserved area of the city. Our refocusing of the project in this instance came in encouraging Alonso to consider the scale of the neighborhood and its residents. Alonso was able to integrate these concerns with the social and cultural aspects of the neighborhood through onsite interviews and fieldwork. Through this investigation Alonso identified the local market as the context in which to connect the large scale, and potentially top down infrastructure project he had proposed, to the human scale and everyday lives of residents.

Filiberto Viteri's personal connection with the context of his project focused his research and design investigations, as well. At age 17 as a college student, he moved to Ecuador's largest city, Guayaquil, from the small city where he grew up. He had great difficulty finding housing in the city and realized he was competing with thousands of other ruralto-urban migrants. He observed how they had brought their rural ways of life to the city environment and how as squatters they often degraded the environment. Although his undergraduate architectural education in Ecuador addressed housing, it did not address issues of culture and socio economic support for migrants and also failed to address a number of important infrastructure questions. These problems were framed at two scales. On the one hand Viteri needed to understand the large- scale economic situation faced by rural-urban migrants in Ecuador, how migrants solve these problems and how attempts to ameliorate them are made by the government. At the same time, Viteri needed an understanding of the micro-scale residential contexts that form the everyday existence of migrants to Guayaquil. This represented, as in each of the other projects, a new and difficult challenge as we were unwilling to allow Viteri and the others to disregard or downplay the largescale or small-scale implications of their design interventions.

Joe Simon's choice of project and direction was strongly influenced by his experience with the 2010 Illinois Solar Decathlon team. Simon chose to explore the intersection of economic affordability and ecological sustainability in an effort to understand how long-term cost benefits accrued through energy savings might influence affordability. Simon's initial research led him to recognize that current models for affordable housing neglect the long-term energy costs for residents favoring lowcost construction. Simon's design process proceeded based on the premise that design decisions influencing long-term energy costs were as important in determining affordability as initial costs of construction. This question of up-front versus long-term costs was continually framed by the need for an understanding not just of economics, but also of the neighborhood scale and the needs of neighborhood residents for development that offered them the opportunity to live affordably. These concerns expanded the project questions to include transportation options, employment opportunities and social infrastructure like daycare facilities and after-school spaces. These concerns complicated the solution space available to Simon and led to a project that rather than being focused solely on economics became instead a project about sustainable community development in which long-term economic sustainability was linked to specific building scale solutions.

\section{Methods}

In each case the students were encouraged to support their design explorations with a core of research knowledge. Each student used a mix of research methods, but the research strategies that guided the use of these methods during the research phase of the projects were generally of two types. Three projects were based on an archival strategy that looked at historical data. The students used these data to extrapolate future conditions. They then formulated a design response to ameliorate the negative consequences within those future conditions. The second strategy was scenario based. Using this strategy, students developed multiple design scenarios that then, using an appropriate simulation, were tested quantitatively for their ability to achieve the desired outcomes. Greenlee, Viteri, and Alvarado used the archival strategy. Greenlee's research sought to understand the value of arable land in central Illinois as a food production resource and to re-internalize costs associated with low-density suburban development. Looking at a range of data including food production, global food consumption linked to Illinois agricultural production, historical trends in urban expansion, population growth and 
farm productivity in the face of global warming, Greenlee concluded that Illinois farmland is far more valuable than the current monetary value placed on it when sold for low-density suburban development. An example of his findings can be seen in Figure 1 where Greenlee shows the global reach of Illinois (in red) agricultural products, highlighting in orange countries contributing more than $\$ 10$ million to Illinois agricultural exports. This research suggested the import of investigating development strategies that curtail consumption of arable land for suburban housing development.

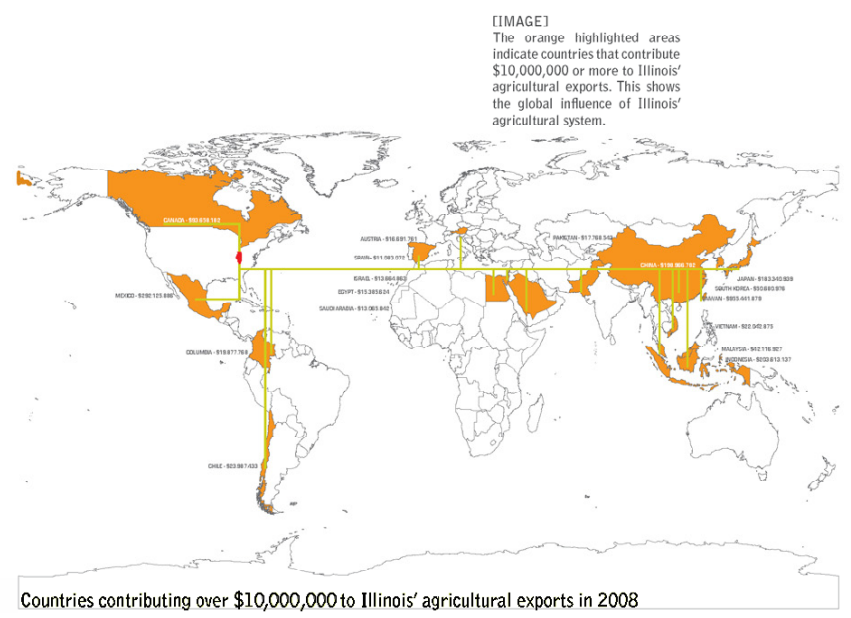

Figure 1: Greenlee - Global Distribution of Illinois Agricultural Exports (source: Camden Greenlee)

Viteri's research sought to understand the relationship between the social and economic conditions that lead to migration to Ecuador's largest city and the resulting urban settlement patterns. His investigation of housing and settlements in rural Ecuador provided information needed to respond to both the migrants' aspirations and their physical needs. Anchored in an historical analysis of the city's growth shown in Figure 2 , its colonial past, globalizing present, and Ecuador's rural vernaculars, Viteri's research informed the design of a new housing form and pattern of development that contrasts the typical government housing schemes shown on the right in Figure 2. Viteri's research addresses the macroscale influx of migrants from the countryside to the city, the fragile ecological zones in tracts along the Guayas River, and the micro-scale needs of these migrants.

Through his research, Alvarado sought to understand both the technological and political decisions that have led to the socially inequitable conditions in Mexico City, the world's third largest urban agglomeration. It seemed incongruous that a city that sits on a lakebed suffers daily water shortages. Likewise, that a shortage of affordable fresh fruits and vegetables exists in a city surrounded by vast, highly
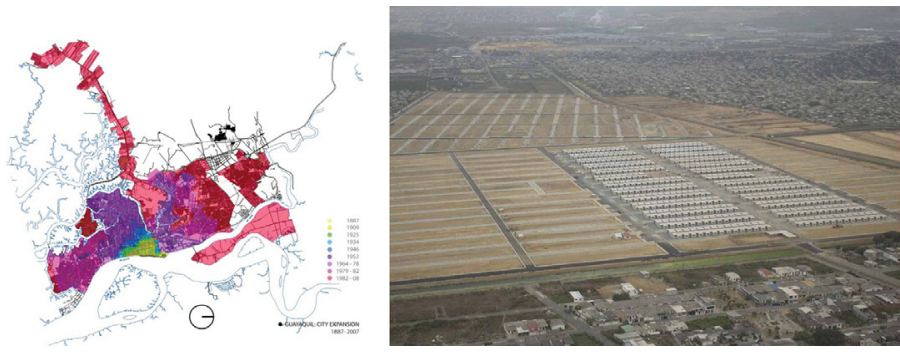

Figure 2: Viteri - Guayaquil City Expansion 1887-2007 (left), with typical government housing scheme for migrants (right) (source: Filiberto Viteri)

productive agricultural lands. Alvarado studied historic photographs of the city's surface-level canal system as well as documents detailing the city's decision to bury the canal system in a deep tunnel infrastructure that pumps water beyond the mountains surrounding the city shown in Figure 3. Through this investigation, Alvarado gained a greater understanding of the negative consequences of maintaining the current infrastructure that fails frequently, leads to dangerously polluted agricultural lands outside the city as well as failing to provide potable water or adequate fresh food to city residents. He then examined several urban development schemes that could ameliorate the long-term negative consequences of current and future conditions for Mexico City's nearly nine million residents.

Wallon and Simon used a scenario-based strategy. In each of these projects multiple scenarios were developed to understand the consequences of site-scale design decisions on the project's ecological sustainability. After testing these scenarios both projects then proceeded to detailed investigations of building and site designs to support ecological as well as social and economic measures of sustainability.
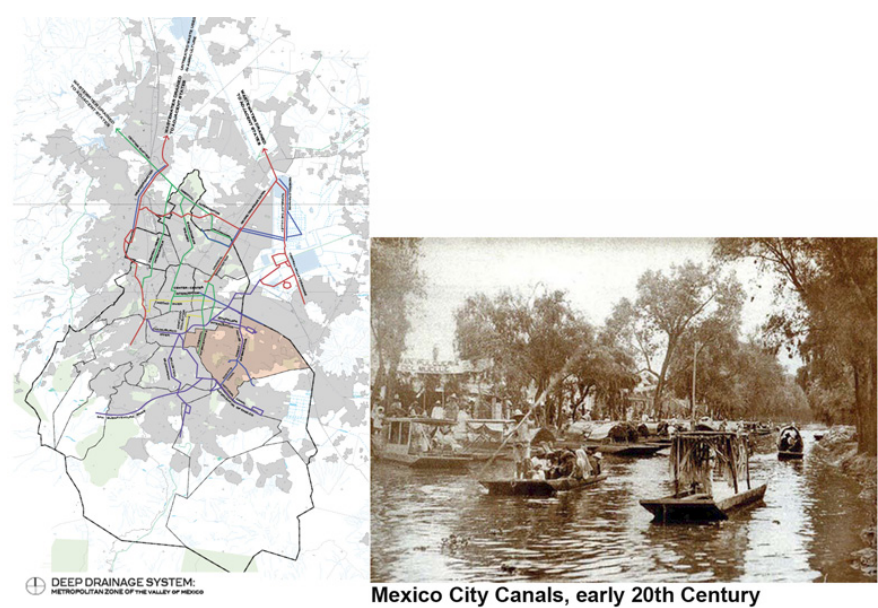

Figure 3: Alvarado - Current and Historic Solutions to Mexico City Water Drainage (source: Alonzo Alvarado) 
In Simon's project three scenarios were developed for the 13-acre site in Southwest Washington D.C. each of which was analyzed in Autodesk Ecotect. These scenarios, seen in Figure 4, included a typical large block development, a small block development and a hybrid development. Building construction type and materials were held constant in each scenario with orientation and massing changing in each case.

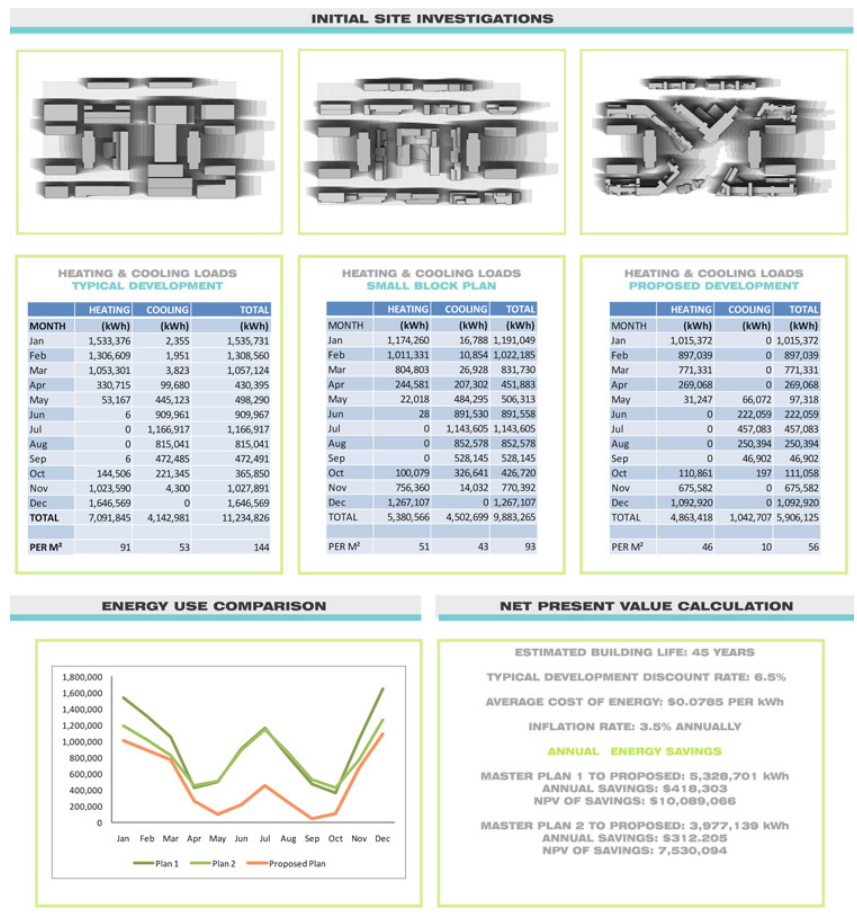

Figure 4: Three Scenarios by Joe Simon (source: Joe Simon)

Simon's analysis of these scenarios indicated that the hybrid approach afforded considerable potential energy savings over the life of the building that would accrue to building residents thereby improving the lifecycle affordability of any individual unit. While, as Simon notes in his documentation of the scenario analysis, the savings may not completely offset the initial increased construction cost for the hybrid design, other features of the master plan, highlighted below, present opportunities to improve aspects of urban sustainability for residents.

Wallon followed a similar method in his treatment of the 29-acre site on the campus of the University of Illinois were he proposed a living/learning dorm complex that challenged the prevailing double loaded corridor, doughnut configurations currently used widely for dorm construction due to their increased circulation efficiency and therefore lower first costs. Using a simplified single loaded corridor building configuration and the energy saving from solar gain with this configuration, Wallon calculated a thirteen-year payback on the $39 \%$ increased construction costs for the single loaded corridor configuration when compared to construction estimates for the architect's newly proposed dorms for the site.

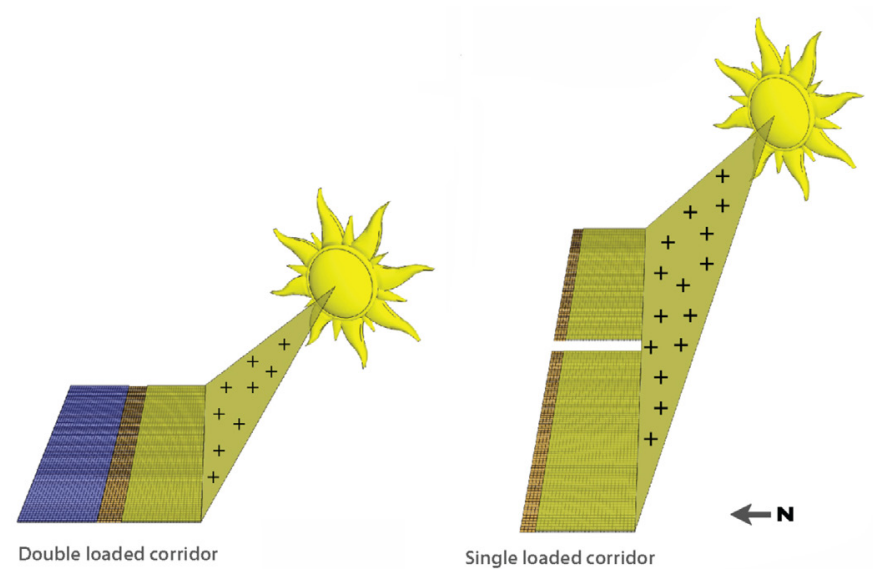

Figure 5: Wallon's Energy versus Construction Cost Scenario Simulation (source: Steve Wallon)

Given the lifecycle of the dorms, the current dorms on the site have been in place for over 60 years, the cost savings to the University from a single-loaded-corridor proposal like Wallon's would be considerable. Wallon further substantiated these initial findings by comparing the single and double loaded scenarios using the energy-modeling program Energy Plus and DesignBuilder. This more detailed analysis increased the payback time to 29 years but still represented a significant savings for the University over the life of the building. Like Simon's, findings, the single-loaded corridor proved not only advantageous in terms of heating and cooling load savings but also afforded further design opportunities in keeping with the social and cultural aspects of a living/ learning environment, including increased opportunities for daylighting and social interaction. Wallon applied Festinger's theory of "maximizing passive contacts" (Back, Festinger, \& Schachter, 1963) in considering dorm layout to maximize social interaction potential for residents and, as Festinger showed, to increase the number of other residents student consider as acquaintances. Wallon demonstrated that his single-loaded corridor scheme offered twice as many opportunities for social interaction as did the double loaded corridor, doughnut configurations of the dorms newly proposed by the University's architect. Thus Wallon's scenario not only improved energy cost savings but offered greater opportunities for residents to build social relationships.

\section{Outcomes}

These projects' outcomes were as varied as the motivations that underpinned them and the variety of research methods that supported the design decisions made by the students throughout the semester. What links them is their reliance on research findings and the determination to envision a sustainable urban future that ameliorates the problems identified through the research.

The final design solution formulated by Camden Greenlee was founded on his desire to identify alternatives to developing prime arable farmland. 


\section{ESTABLISHING SITE}

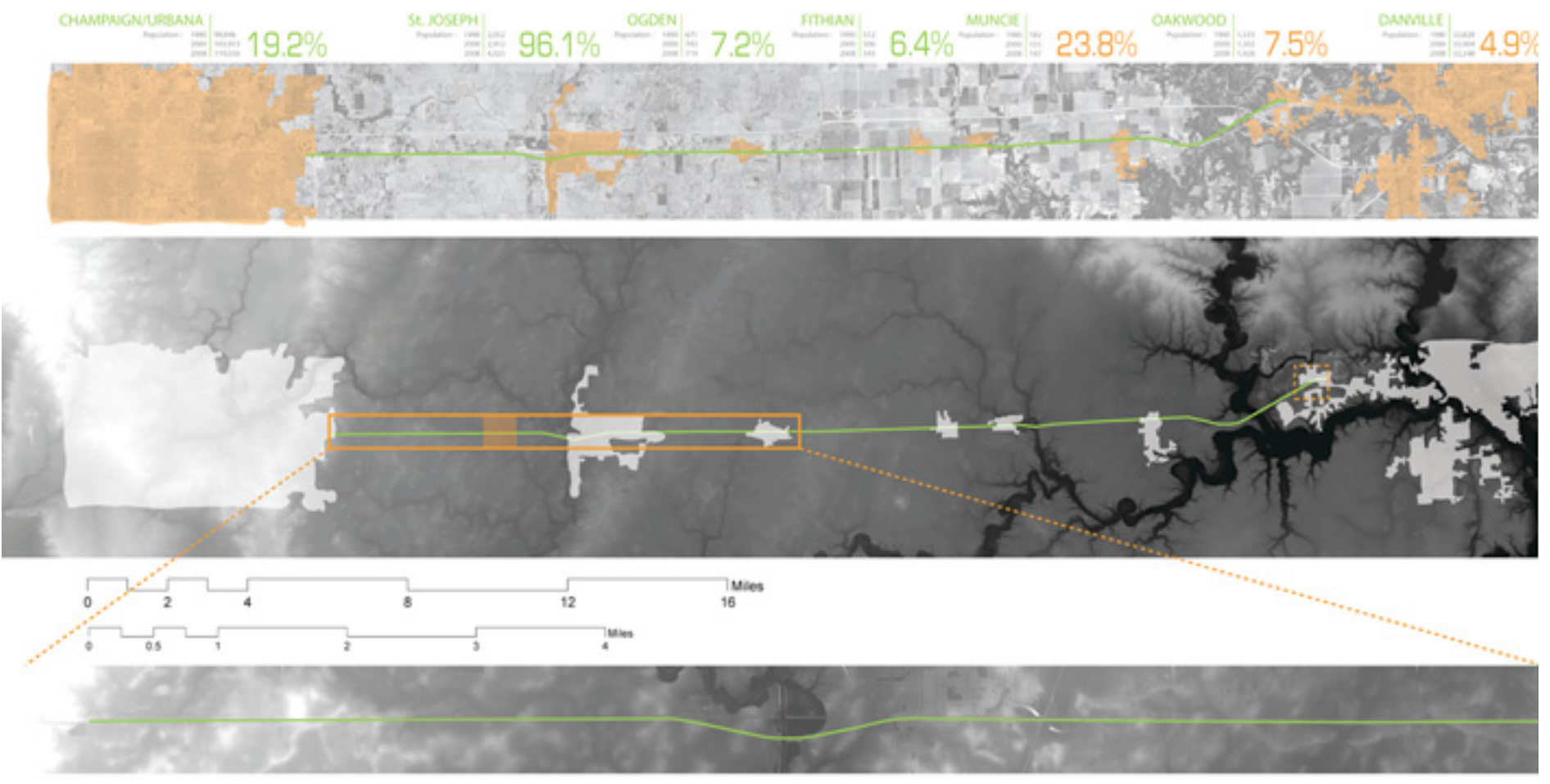

Figure 6: Greenlee's Project Site (source: Camden Greenlee)

Greenlee's first step in his solution to this problem was to identify a brownfield site for the project. He identified a unique brownfield, an abandoned railroad right-of-way that connected the central Illinois towns of Champaign-Urbana and Danville. Greenlee calculated that the 25 mile long by approximately $175 \mathrm{ft}$. wide strip of land, seen in Figure 6, could accommodate population growth for Champaign-Urbana for 18 years if developed with a density of 10 persons/acre. By limiting his proposal to this brownfield site, no arable land was developed within the proposal.

Greenlee's phased design proposal integrated a Personal Rapid Transit (PRT) system along the length of the site and envisioned a program of housing and amenities at strategic nodes along the length of the project. These nodes focused on the existing small towns that are already becoming bedroom communities for Champaign-Urbana. Greenlee's goal for the residential environment was to provide a variety of housing types that would appeal to a wide demographic but especially to those who would otherwise enter the suburban housing market. Seen in Figure 7 , this housing breaks the linear site into smaller sub-nodes that are identified with the principal stops of the PRT. Borrowing views from the surrounding agricultural land, Greenlee's proposal gives visual ownership to the landscape without impacting the arable land. In addition, careful consideration of site orientation affords opportunities for the integration of passive solar techniques.

Greenlee's proposal envisions a new land development paradigm to accommodate population growth, one that is not reliant on the car and which preserves the food production capacity of some of the world's most fertile agricultural land. While this proposal may be critiqued as beyond the means of today's economics and unpalatable to the housing

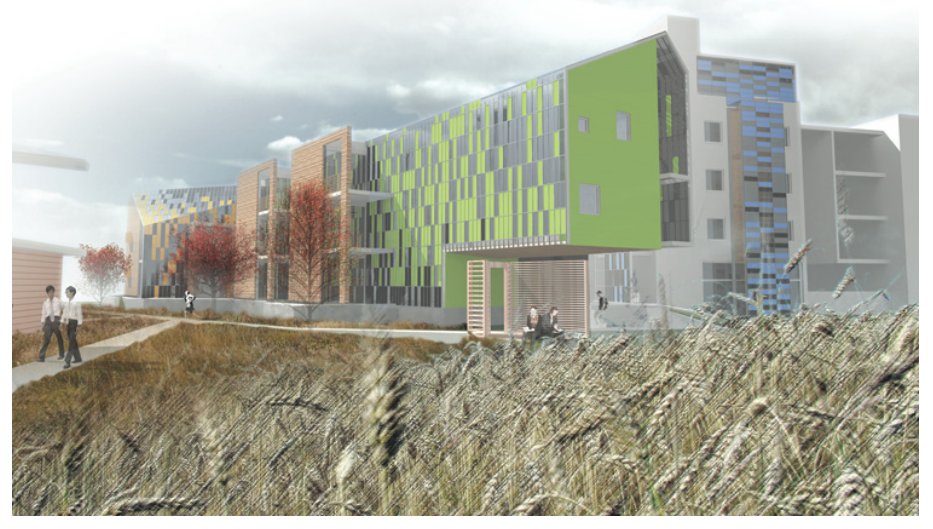

Figure 7: Greenlee's Proposed Housing Node (source: Camden Greenlee) 


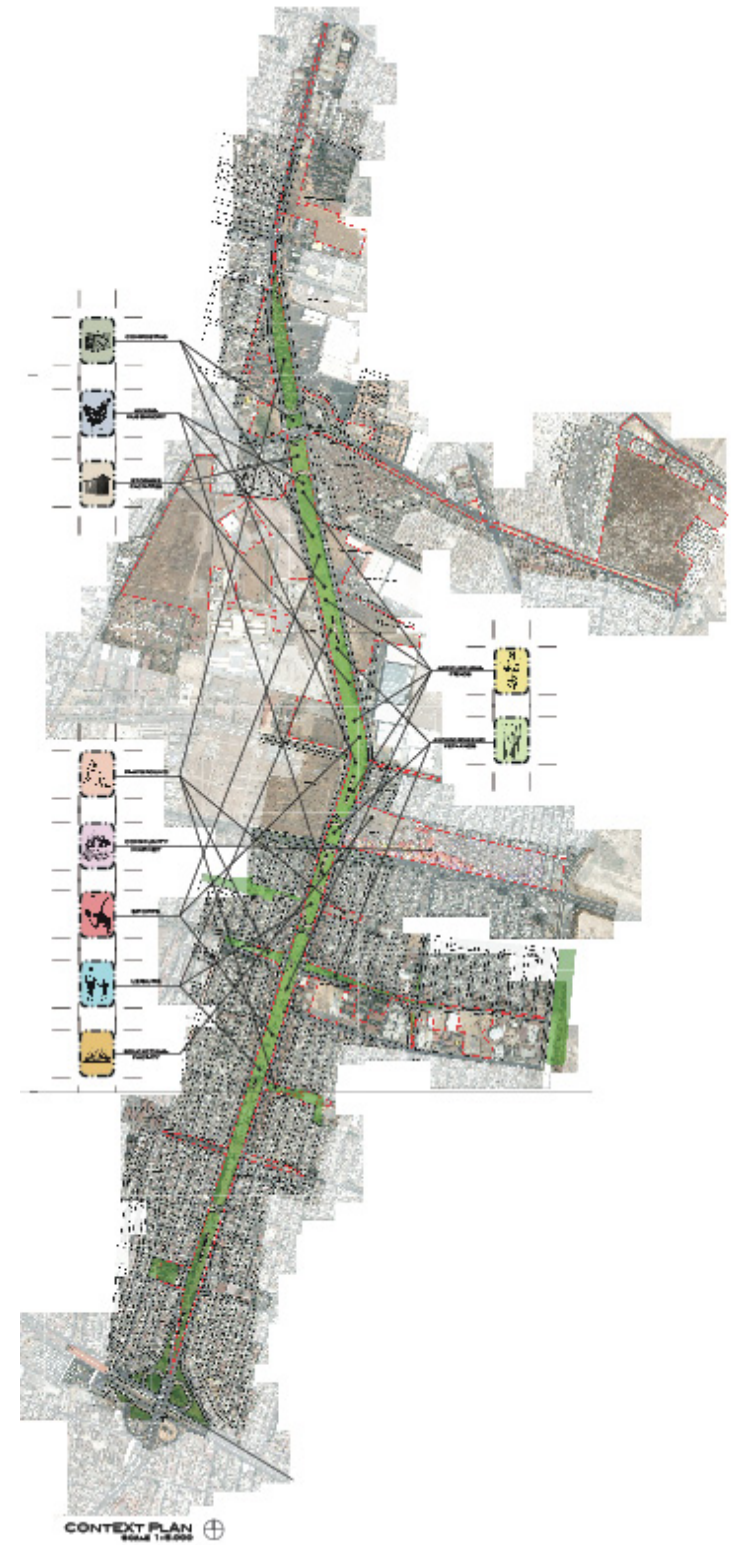

Figure 8: Alvarado's Chinapas Spine along the the Anillo Periferico, Mexico City (source: Alonzo Alvarado)

market, both critiques faced by Greenlee from outside reviewers, Greenlee's research makes clear that the increasing importance of food production for a global population will necessitate a new vision for housing while maintaining agricultural land. Indeed it seems possible, given the evidence Greenlee marshaled in the research phase of the project, that current patterns of suburban development will likely become economically unviable as the cost of arable land increases.

Alonso Alvarado's design intervention in the Federal District of Mexico City began at the broadest scale by leveraging information about the city's water and canal system to identify a suitable site for a productive landscape zone, supporting food-crop cultivation within the city. Alvarado identified a four kilometer strip of land bounded by one of the city's principal thoroughfares, the Anillo Periferico, and under which runs the Orient-South Interceptor, part of the city's deep drainage system. Alvarado proposed the development of a three zone constructed wetland for water treatment followed by a series of Chinapas, a system of indigenous wetland agriculture, along this strip, seen in Figure 8.

Alvarado proposed a series of community amenities along this spine including playgrounds, parks and markets. Focusing on one of these markets, Alvarado developed a detailed proposal for the openair market that is known as the El Gran Tianguis de las Torres in the Renovacion neighborhood. In this proposal Alvarado attempted to provide infrastructure to the market where none exists today. While these markets play a vital role in providing a livelihood to many residents, they are technically illegal and operate outside of the formal economy. Alvarado envisioned this market as providing the link to the Chinapas system developed along the spine. In addition the new market halls ameliorate the current poor working conditions of the marketers who

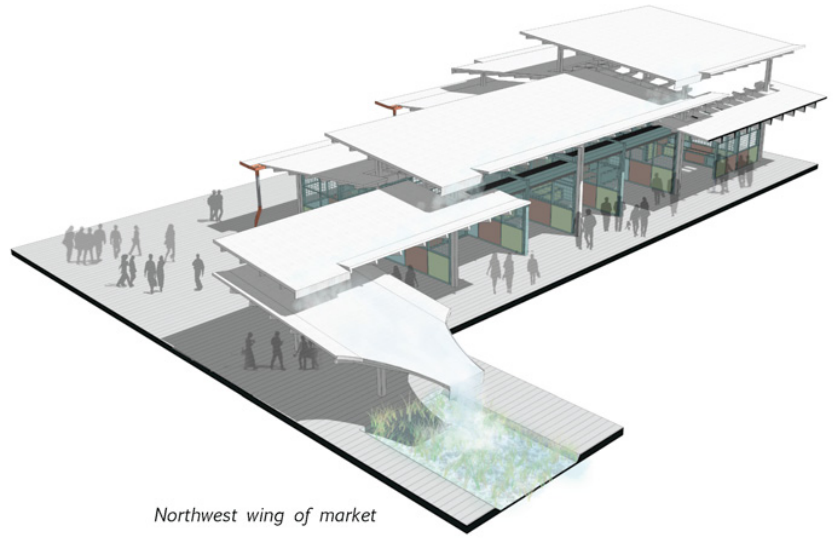

Figure 9: Section of Market Hall at El Gran Tianguis de las Torres (source: Alonzo Alvarado)

suffer a variety of ailments from pollution and poor sanitation. The market halls, five in all, are grouped according to goods sold and provide toilet and meeting facilities. Between these market halls Alvarado proposed a series of less structured marketing areas where the informality that is an important social and cultural part of the markets can continue.

Alvarado's proposal relied heavily on the historical research of Mexico City's hydrology and of its historic agricultural systems. In addition his interviews with marketers allowed him to approach the problem with sensitivity to the social and cultural context. His invocation of historic 
and indigenous forms of agriculture and development and his linkage of the urban scale water and food problems with the micro and everyday scale, within the confines of one of the world's most populous megacity's, is indicative of the new more comprehensive approaches to sustainable urban futures that today's designers must take.

Similar to Alvarado's comprehensive approach, Filiberto Viteri's design proposal responds to a set of social, cultural and environmental concerns present in the Ecuadorian city of Guayaquil. Responding to and countering the prevailing government development paradigm revealed in Figure 2, Viteri proposed an integrated design solution for migrants to the city that addressed both the physical and socio-cultural aspects of housing. At the same time he recognized the need to link the economic livelihood of these new residents to a concern for the natural environment. To achieve this linkage, Viteri's housing invoked indigenous materials and spatial layouts while also responding to migrant aspirations for modern housing imagery that separates them from their rural origins.

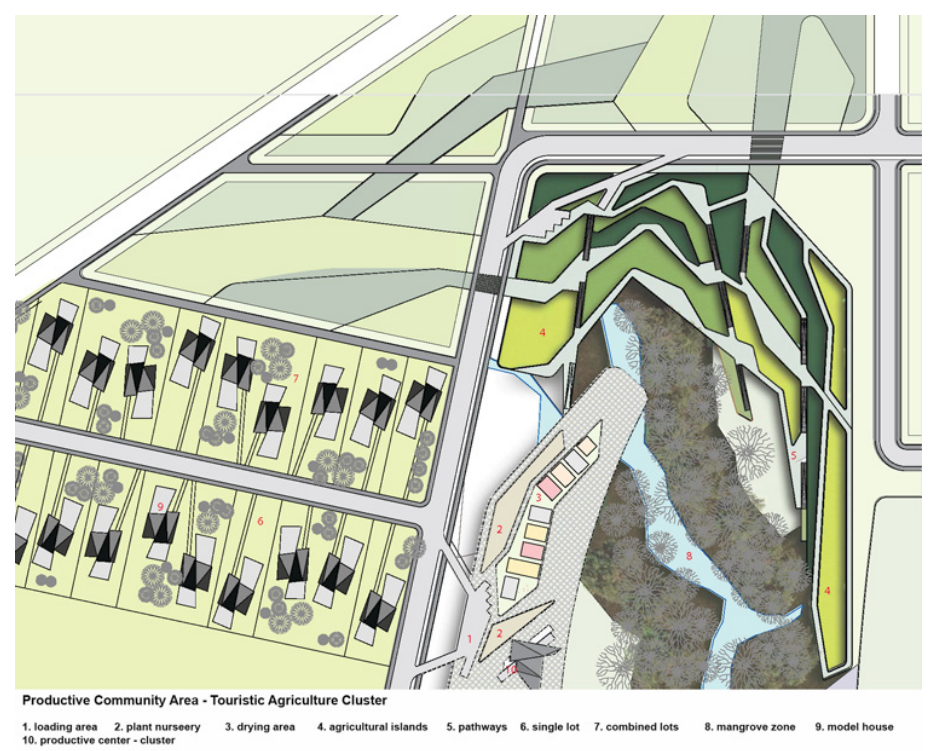

Figure 10: Viteri's Proposal for one Productive Community Area (source: Filiberto Viteri)

Viteri addressed the economic and ecological sustainability of the problem simultaneously, by proposing a series of work zones or "productive community areas" along the river, as seen on the right in Figure 10. Residents are employed in a variety of enterprises in these work zones including, for example, farming, hat making, pottery, and building component manufacturing. At the same time these areas function as a buffer zone for the remaining mangroves along the river's edge. These mangroves serve an important ecological function in the health of the river's north bank. In such area, mangroves are often encroached upon by squatters, degrading the riparian landscape. Viteri's proposal addresses one the developing world's most pressing issues at the intersection of urbanization and sustainability. By integrating vernacular and historic responses to housing with a broader definition of sustainability that includes both social and economic aspects, Viteri challenges the typical sites and service paradigm prevalent in the developing world.

The most significant outcome of Joe Simon's scenario based research exploration was at the masterplan scale. The findings that the hybrid urban plan that was neither broken into many smaller scale buildings nor a more typical build-out of the site using larger building blocks, runs counter to prevailing housing development standards. It also offers the possibility of greater individual identity for buildings and thus for the residential units within those buildings.

Simon's affordable housing proposal for southwest Washington integrated a mix of uses, income levels, and unit sizes. The proposed mix of unit sizes and income levels was a direct response to Simon's analysis of populations underserved within Washington D.C's market rate housing developments. He was also responding to the current population in the Southwest district who tend to be lower-income and larger households on average than in other parts of the city. The mix of uses responded to key issues of affordability that are often overlooked in affordable housing development. These included lifecycle energy costs, proximity to public transportation, amenities like daycare, and employment opportunities created within the development through the mixed uses.

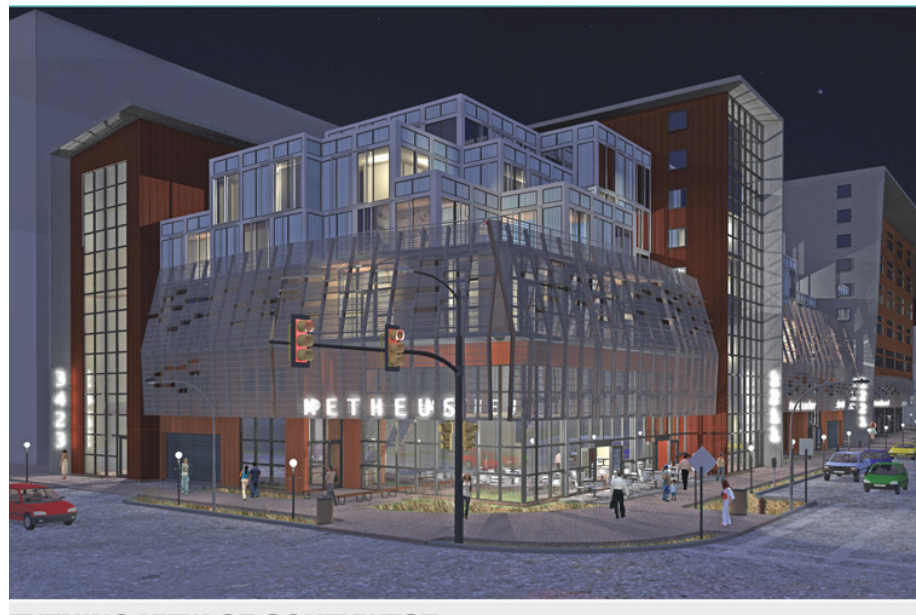

EVENING VIEW OF SOUTHWEST

Figure 11: Simon's Proposal (source: Joe Simon)

Simon's proposal also leveraged the burgeoning redevelopment opportunities in Southwest Washington including the nearby Nationals' Ballpark. Simon's masterplan responds to the opportunities presented by the Washington Metro's station on site. This station is the closest to the new stadium and affords opportunities for a range of commercial development as part of the mix of uses proposed. 


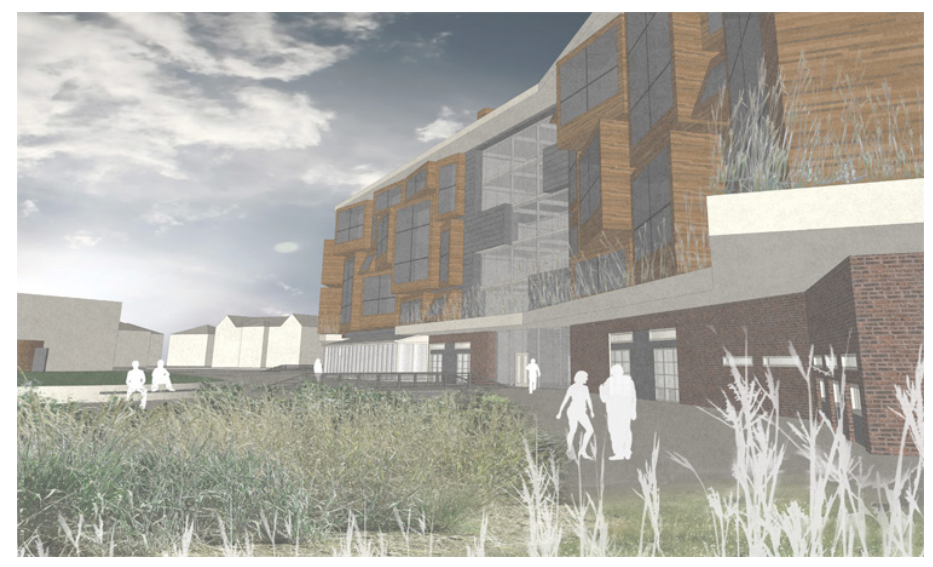

Figure 12: Wallon's Proposal illustrating Sustainable Landscape and Interiorexterior connections (source: Steve Wallon)

Simon's proposal offers a new model for affordable housing that takes into account not only first costs but also the long-term prospects for a socially and economically sustainable community and the lifecycle affordability of housing units. By asking larger scale questions about what affordability means in the research phase of the design, Simon was able to identify several often overlooked aspects of affordability and link them to measures of community and individual sustainable livelihoods during the design phase. The solution he proposed gives residents not only a long-term energy cost savings, but a community in which they can achieve their individual sustainable futures.
Steve Wallon's personal history in campus housing focused his preliminary investigations for his project on physical and social comfort for residents. His professional interest in ecological aspects of sustainability broadened his approach so that his developing master plan proposal for dormitory redevelopment on the University of Illinois Urbana-Champaign campus increasingly responded to the goals of creating an environment where students were continually introduced to aspects of development and lifestyle that promote a diminishing carbon footprint.

While Wallon's master plan was initially generated from the single loaded corridor scenario in order to take the fullest advantage of solar orientation, this master plan had several benefits that were leveraged by Wallon in the final design. Principal among these were the opportunities for social interaction within the living/learning environment and the ability to create an integrated sustainable landscape that re-conceptualized the relationship of residents and their surroundings. Like the single loaded corridor plan substantiated by Wallon's research, this approach to the landscape runs counter to the typical campus landscapes where manicured lawns and subsurface drainage systems are the norm. The result, seen in Figure 12, is a landscape much more reminiscent of the historic prairie landscape of Central Illinois. Student residents of this dormitory complex would experience this landscape on a daily basis as they moved around the complex and to classes in other parts of campus. Another of Wallon's atypical responses to infrastructure, that would introduce and educate students about how to diminish their ecological

Figure 13: Wallon's proposal offers many opportunities for student social interaction (source: Steve Wallon)

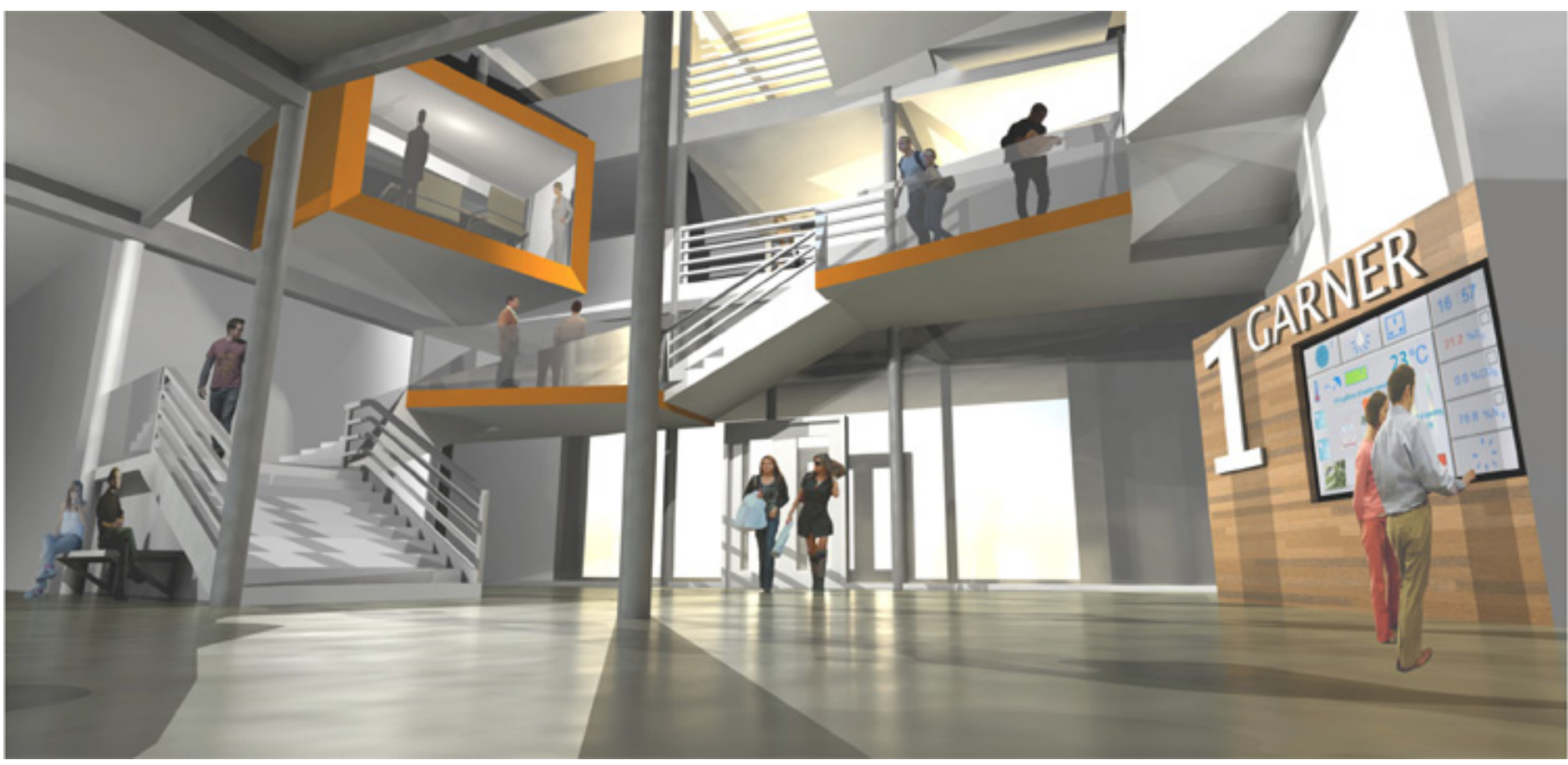


footprint, are the living machines that are part of the dorm environment. Living machines are scaled to treat all human waste generated on site. As part of the learning that would take place in the dorm environment, students would play an active role in maintaining these systems.

Throughout the master plan, Wallon emphasized the creation of social spaces that would facilitate student interaction. In the exterior sustainable landscape there are small gathering spaces. As well there are many connections between interior and exterior afforded by large south-facing windows and transitional spaces that sit at the edge between exterior and interior. Within the buildings Wallon emphasized informal social spaces using circulation paths as opportunities for students to interact as Figure 13 shows. Once again this configuration of space runs counter to the admitted more efficient corridors of a typical dormitory. However, as Wallon's research on student wellbeing demonstrates the benefits of such interactions cannot be overstated.

\section{Conclusions}

The framework that set the tone for this studio referenced theories of bioregionalism and ecological design (Orr, 1994; Thayer, 2003; Van Der Ryn \& Cowan, 2007). This framework also built on dimensions of place and place-based strategies for development. Within this framework the range of students' project types and their diverse geographic locations allowed for a rich dialogue concerning alternative modes of urbanization to develop within the studio. The resulting projects provide an expanded vision of what sustainable forms of urbanization may look like and the means to achieve them. With our urging students questioned the ways in which the social, economic, cultural, political, and environmental domains serve to determine whether and how the built environment is sustainable. Invoking a wider set of design variables provided by considering multiple domains of evidence at multiple scales expands considerably the problem space while at the same time affording the designer a much larger solution space. Furthermore it complicates how one might measure the sustainability of any given solution at various geographical and physical scales. At the same time we were reminded often of the need to continually refocus the student designers on the architectural scale and what the larger scale issues meant for their architectural propositions.

In asking more complex questions about the built environment and searching for evidence to answer them, these five students, with our guidance, have transgressed disciplinary boundaries to bring the widest possible range of information to bear on their design solutions. They questioned the status quo and considerably expanded their notions of what is sustainable. We believe, as these student projects have begun to show, that this approach, based on a rigorous research foundation, can lead to more sustainable urbanization along the multiple dimensions by which such a future must be measured.
The authors wish to thank Camden Greenlee, Joe Simon, Alonso Alvarado, Steve Wallon and Filiberto Viteri for allowing them to detail their projects in this article and wish them good luck as they embark on their careers in environmental design.

\section{References Cited}

Back, K., Festinger, L., \& Schachter, S. (1963). Social Pressures in Informal Groups. Stanford: Stanford University Press.

Canter, D. (1977). The Psychology of Place. London: The Architectural Press, Ltd.

Hamm, B., \& Muttagi, P. K. (1998). Introduction. In B. Hamm \& P. K. Muttagi (Eds.), Sustainable Development and the Future of Cities (pp. 1-16). London: Center for European Studies with ITDG Publishing.

Orr, D. W. (1994). Earth in Mind. Washington, DC: Island Press.

Schneekloth, L. (1998). Unredeemably Uropiam: Architecture and making/Unmaking the World. Utopian Studies, 9(1), 25-49.

Thayer, R. (2003). LifePlace: bioregional thought and practice Berkeley: University of California Press.

Van Der Ryn, S., \& Cowan, S. (2007). Ecological Design (10thAnniversary ed.). Washington, DC: Island Press. 